Allpanchis, año XLVIII, núm. 88. Arequipa, julio-diciembre de 2021, pp. 13-46.

ISSN impreso 0252-8835 / ISSN en línea 2708-8960

DOI: https://doi.org/10.36901/allpanchis.v48i88.1323

\title{
dossier
}

\section{Familia, patronazgo y redes de poder en el cabildo catedral del obispado de Popayán, 1600-1728}

\author{
Carolina Abadía Quintero \\ Universidad del Valle (Cali, Colombia) \\ carolina.abadia@correounivalle.edu.co \\ Código ORCID: 0000-0003-0284-8366
}

\section{RESUMEN}

Los cabildos eclesiásticos cumplieron un rol determinante en la administración eclesiástica de los obispados indianos, pues fue la corporación en la que se posicionaron integrantes de grupos familiares locales como estrategia para adquirir poder y prestigio, o una merced del rey, apelando a los recursos de promoción eclesiástica dictados por el Regio Patronato. ¿Es posible identificar este modelo de prácticas en el cabildo catedral de Popayán? ¿Cómo influyen en la promoción de un eclesiástico su linaje familiar o el apoyo de un protector? El objetivo de este texto es mostrar cómo, en el siglo XVII, destacan diversos casos de redes y linajes que lograron una prebenda en el cabildo catedral payanés, para esto se han 
consultado documentos del Archivo General de Indias y el Archivo Central del Cauca, los cuales permiten comprender que el cabildo catedral payanés no estuvo exento de este tipo de lógicas políticas vinculantes.

Palabras clave: redes de poder, patronazgo, Regio Patronato, cabildo catedral, promoción eclesiástica

Family, patronage, and power networks in the cathedral cabildo of the bishop of Popayán, 1600-1728

\begin{abstract}
The ecclesiastical councils played a decisive role in the ecclesiastical administration of the Indian bishoprics since it was the corporation in which members of local family groups positioned themselves as a strategy to acquire power and prestige, or a grant from the king, appealing to the resources of ecclesiastical promotion dictated by the Regio Patronato. Is it possible to identify this model of practices in the cathedral chapter of Popayán? How does the promotion of an ecclesiastic influence his family lineage or the support of a protector? The objective of this text is to show how in the seventeenth century, various cases of networks and lineages that achieved a prebend in the Pagan cathedral chapter stand out, for these documents from the General Archive of the Indies and the Central Archive of Cauca have been consulted, which allow us to understand that the Payanese cathedral chapter was not exempt from this type of binding political logic.
\end{abstract}

KEYwords: power networks, patronage, Regio Patronato, cathedral chapter, ecclesiastical promotion

\title{
INTRODUCCIÓN
}

El CABILDo CATEDRAL es DEFINIDo por Óscar Mazín como «un verdadero senado de los obispos» (1996, p. 13), por lo que su importancia como corporación eclesiástica fue vital en la tarea de administrar y gobernar obispados y arzobispados en el mundo his- 
pánico, y en la promoción de prebendas, proceso dictaminado por el Consejo de Indias gracias al Regio Patronato. Las prebendas que conformaban la planta de los cabildos catedrales se convirtieron en los cargos más apetecidos por los clérigos que deseaban un ascenso dentro de las corporaciones de la alta clerecía indiana. En la primera mitad del siglo XVI, en los capítulos catedrales fueron nombrados clérigos de origen peninsular, no obstante, a medida que se fortalecieron las nuevas elites en las ciudades indianas, estas, en un reclamo asentado en los servicios y méritos que habían prestado a la Corona en el proceso de conquista y poblamiento de los nuevos territorios, y apelando a la reciprocidad y gracia del rey, solicitaron nombramientos de familiares y descendientes en distintos estamentos, incluidos por supuesto los cabildos catedrales.

Esta situación ha sido estudiada de manera amplia para la Nueva España por investigadores como Óscar Mazín (1991, 1996, 2007), quien desde el análisis histórico de larga duración analizó las vicisitudes del cabildo catedral del obispado de Valladolid de Michoacán, y por Leticia Pérez Puente (2005), Rodolfo Aguirre (2004, 2008) y José Gabino Castillo (2013), quienes en diversos momentos del periodo virreinal han trabajado el cabildo catedral de la Ciudad de México. En la historiografía española hay diversos e importantes análisis sobre la incidencia en las carreras eclesiásticas de prebendados y capitulares de relaciones familiares (Imízcoz, 2001) y de patronazgo (Artola, 2011, 2017), como también para el caso de los eclesiásticos y cabildos catedrales en Chile en el siglo XVIII (Enríquez, 2004, 2005). Estos trabajos resaltan la importancia de estudiar los cursus honorum de los capitulares que pertenecieron a los cabildos catedrales, indagando sobre sus relaciones familiares y la incidencia de estas en las recomendaciones a cargos, y los vínculos de estas familias con otros grupos y corporaciones del poder local y virreinal.

Por cédula firmada por el emperador Carlos V, el 22 de agosto de 1546 se creó el obispado de Popayán y se designó como primer obispo a Juan del Valle, quien entre sus primeras obligaciones 
ordenó la constitución de su iglesia y del cabildo catedral el 8 de septiembre de 1547, estableciendo inicialmente que la planta catedralicia estaría conformada por veintisiete prebendas que comprendían cinco dignidades —deán, arcediano, chantre, maestrescuela y tesorero-; diez canónigos, seis racioneros y seis medioracioneros (Ortiz y Bueno, 1945, p. 140); planta que en menos de dos años disminuiría, primero por las bajas rentas decimales del obispado que no permitían el mantenimiento de tantas prebendas, y segundo, por la dificultad de desplazamiento de aquellos capitulares que habían sido elegidos para ocupar cargos en el cabildo catedral de Popayán. Así, en lo que restó del siglo XVI, como revelan las consultas del Consejo de Indias y varias reales cédulas de nombramiento, los prebendados de la corporación catedralicia fueron de origen peninsular; no obstante, para el siglo XVII es posible rastrear capitulares nacidos en ciudades del obispado de Popayán, el Nuevo Reino de Granada y los reinos del Perú, de hecho Abadía propone que, para el caso del obispado de Popayán, se identifican tres etapas de presencia capitular criolla y española entre los siglos XVI al XVIII: una primera etapa establecida en el siglo XVI, «en la que los cargos fueron ocupados por españoles»; la segunda en el siglo XVII, «en la que se revela una propensión de nombramientos por naturales de la tierra; y un último momento [en el siglo XVIII] en el que los criollos ocuparon mayoritariamente las dignidades del cabildo catedral» (2019, p. 82). Para el caso de los cabildos catedrales de la Nueva España y de los reinos del Perú, se presentan diferenciaciones con respecto al origen de sus integrantes ligadas al carácter de cada sociedad, a las distancias y dificultad del viaje, y lo atractivo en términos económicos de los beneficios eclesiásticos (Ganster, 2016, p. 180), así, en el caso de los cabildos eclesiásticos peruanos contrario al caso novohispano, su sociedad, como refiere Ganster, era más estable y cerrada, por lo que las familias de elite apelaban a sus linajes y a los servicios de los antepasados para solicitar nombramientos al rey (2016, p. 181), peculiaridad que también fue identificada en el análisis de la composición del cabildo catedralicio payanés. 
Este vínculo evidente entre las nuevas elites indianas y la Corona se explica en la idea de intermediación que existía entre la administración monárquica y las corporaciones de diversa índole (Martínez Millán, 1996, p. 89), existentes en los territorios del rey. Esta concepción corporativa de la monarquía, en palabras de Martínez Millán, se definía «más por las relaciones personales que por relaciones institucionalizadas» (1996, p. 94), y es en esa esfera en donde se resignificaban los méritos y servicios prestados en nombre del rey, que son prueba de la fidelidad a un cuerpo político, en este caso el de la monarquía y del honor, virtud fundamental para comprender las actitudes y comportamientos políticos y socioculturales de la época.

En este sentido, este artículo, a partir de la exposición de estudios de casos centrados en las dinámicas históricas del cabildo catedral de Popayán, analizará cómo los linajes familiares fueron una estrategia de ascenso en la carrera de los eclesiásticos naturales de las Indias, gracias a: primero, los intereses de las familias de elite que lograron afianzar a algunos de sus integrantes en una corporación de importancia como el cabildo catedral, para así crear una red compleja de vínculos en espacios, instituciones y grupos de poder indianos; segundo, el uso histórico del vínculo familiar como un argumento de mérito para optar a un cargo eclesiástico, valiéndose con esto, de manera continua y temporal, de la memoria familiar según las aspiraciones y pedidos de mercedes y cargos; y tercero, el patronazgo ejercido entre prebendados para beneficiar las futuras carreras eclesiásticas de familiares y pupilos. Estas prácticas permiten comprobar que las familias payanesas, desde el siglo XVII, ejercieron una influencia importante en el cabildo catedral, logrando constituir nexos de arraigo local y, con esto, entramados sociales controlados por dichos linajes. Marzahl ha expuesto que la sociedad criolla payanesa se caracterizó por un pedimento continuo de privilegios, por un «refrescamiento» de sus linajes con inmigrantes y por una acumulación de méritos; los tres elementos posibilitaron que 
diversos integrantes de dichos linajes consiguieran nombramientos civiles, recibieran una encomienda o compraran algún cargo público, estableciéndose con esto una continua rotación, «continuidad y movilidad dentro del estrato gubernamental» (2013, p. 135).

Precisamente, uno de los objetivos de esta propuesta es estudiar el acceso de ciertas familias pertenecientes a las elites payanesas en el cabildo catedral de Popayán, desde 1600, cuando se registran los primeros nombramientos de indianos en este cabildo, hasta 1728, cuando se da la promoción a la chantría de Miguel de Castillo, uno de los capitulares que aquí se estudian y quien, como se pudo comprobar en las fuentes históricas, obtuvo el padrinazgo de Miguel de Ressa y Montoya, deán del capítulo catedralicio, para seguir su carrera eclesiástica.

Planteo como hipótesis que parte del fortalecimiento de las elites payanesas se debió a la presencia temprana de varios de sus integrantes en distintas corporaciones de poder local, asegurando además con esto el sustento de las familias y el fortalecimiento de su honor y prestigio en la gobernación y el obispado. Olival y Monteiro, para el caso portugués, afirman que estas situaciones son la demostración de una conexión entre las relaciones de parentesco y las carreras eclesiásticas, condicionándose ambas dinámicas a la presencia de la otra. Por eso es de gran relevancia para muchos capitulares del cabildo eclesiástico de Popayán enunciar sus vínculos e historias familiares, al ser uno de los más poderosos argumentos para aspirar a una promoción y, por ende, a una posibilidad de ascenso social tanto para ellos como para sus familias.

Este artículo apela a los trabajos y reflexiones de la historiografía institucional de la Iglesia católica y de los estudios sobre familias y redes sociales para entender los vínculos enunciados entre familias y cabildo catedral; además, destaca los trabajos sobre redes sociales que aportan el método de estudio, en este caso el análisis relacional, definido por Imízcoz como un tipo de análisis que permite, a partir «de la observación de las acciones e interacciones de los individuos», 
comprender sus nexos en el tiempo y el espacio con estructuras de diversa índole (2017, p. 67). Así, a partir de los datos históricos identificados de los cincuenta y cinco eclesiásticos que ocuparon prebendas payanesas entre 1546 y 1741, y de la metodología propuesta por el análisis relacional, fue posible identificar las relaciones parentales y de patronazgo presentes en relaciones de méritos y servicios, protocolos notariales, consultas del Consejo de Indias y Correspondencias del Archivo General de Indias y el Archivo Central del Cauca. También se apelará al uso del microanálisis y a la reducción de escala (Revel, 1995, p. 129), pues si bien el tema de las estrategias de promoción eclesiástica indiana no es un problema nuevo para la historiografía, sí es novedoso si se formulan preguntas e hipótesis en aquellos obispados y cabildos catedrales considerados de «menor» importancia en la red de catedrales indianas, en tanto permiten retroalimentar la discusión sobre los vínculos de las localidades y sus elites, con las corporaciones de poder de la monarquía.

Este trabajo entiende a la familia del Antiguo Régimen como elemento de intercambio, como generadora de múltiples vínculos, como primera red de solidaridad (Irigoyen, 2018, p. 23), en la que se identifican prácticas sociopolíticas de poder y prestigio vinculadas además a la construcción y al fortalecimiento de capital simbólico (Lindorfer, 2009, p. 265), que sirvió como estrategia de posicionamiento corporativo y burocrático, en la medida en que «buena parte de una carrera eclesiástica estaba definida por los lazos familiares» (Abadía, 2019, p. 513).

El artículo se ha estructurado de la siguiente manera: primero, se presenta el análisis de los argumentos de pertenencia familiar para mostrar su importancia en la elaboración de las relaciones de méritos y servicios, así como en las peticiones de recompensas y mercedes en cargos eclesiásticos por los logros del pasado familiar; segundo, se exponen y analizan las dos redes familiares identificadas en el cabildo catedral de Popayán; y, por último, se presentan algunos casos de patronazgo entre eclesiásticos. 


\section{LA MEMORIA FAMILIAR COMO ARGUMENTO DE SERVICIO}

La promoción eclesiástica fue un proceso determinante en las carreras de los clérigos en el periodo virreinal; como tal, estuvo regida por el Consejo de Indias y el rey gracias al Patronato Regio, y fue consignada en la Recopilación de Leyes de Indias que establecía que el proceso de nombramiento en cargos eclesiásticos del clero secular se haría a partir de la información sobre vacantes disponibles y la presentación de posibles candidatos, propuestos tanto a nivel corporativo por obispos y catedrales como a título personal. En este sentido, el Consejo y la Cámara de Indias en sesión evaluaban las características de la vacante y de los candidatos para elegir una terna que presentaban al rey, quien decidía el nombramiento, el cual era validado por Roma, desde donde se despachaban las bulas que, unidas a una real cédula de nombramiento, constituían los documentos ejecutoriales para que el elegido hiciera posesión formal del cargo.

Aquellos candidatos interesados en recibir una promoción eclesiástica debían remitir al Consejo relaciones de méritos y servicios, en los que se registraban la información del linaje familiar, la limpieza de sangre, los servicios prestados a la Corona y los méritos literarios o religiosos (Macleod, 1998); estas podían además ir acompañadas de recomendaciones de autoridades civiles y eclesiásticas. Aparte, las autoridades provinciales o virreinales comprobaban si los datos presentados en estos documentos eran verídicos, a partir de las informaciones de oficio y parte constituidas por testimonios brindados por personas que conocieran a los remitentes y que validaban la información consignada.

Es posible encontrar como argumento, en diversas relaciones de méritos de capitulares nacidos en Indias, el referido a la memoria de los servicios prestados por sus antepasados. Reconociéndose como «naturales de la tierra», estos clérigos narraban las hazañas de padres, abuelos, bisabuelos y tíos en el proceso de conquista, en las guerras y expediciones contra los indios, en el adoctrinamiento de 
estos, y en el servicio como oficiales reales en algún cuerpo de poder, aunando así la valía propia con los servicios familiares de antaño, recurso discursivo que fortalecía las candidaturas de, por un lado, quienes eran parte de linajes históricos, y por otro, de quienes no tenían mayor mérito que el de sus familiares. Traer a colación la memoria familiar permite, como señala Dedieu, comprender las lógicas de «transmisión de los cargos públicos», y cómo funcionó, lo que este autor denomina como «el reclutamiento de los agentes de la Monarquía» (2005); y también, analizar las recompensas y compensaciones que la monarquía estableció con sus distintas elites, característica fundamental de una monarquía centrada en el «intercambio generalizado de favores y servicios» (Dedieu, 2005) y en prácticas continuas de reciprocidad. Así, si bien el rey no estaba obligado a brindar mercedes, el modelo administrativo de la monarquía hispánica propendía por mantener un equilibrio político con las elites en general, reconociendo en primera instancia los sacrificios hechos por los antepasados de las familias participantes en los procesos de conquista y poblamiento indiano, y brindando mercedes para retribuir la inversión económica y humana hecha por tales linajes familiares. En buena parte de las relaciones, informaciones y peticiones estudiadas de los capitulares del cabido eclesiástico payanés fue posible identificar este argumento de la memoria familiar, que estaba además acompañado de una relación de la pobreza que vivía el capitular y de las obligaciones familiares que poseía con madre, hermanas o hermanos. A continuación, se presentan algunos ejemplos.

El cursus honorum de los hermanos Lucas del Campo Salazar y Andrés del Campo Salazar revela que ocuparon cargos eclesiásticos en la catedral de Huamanga y de Popayán (Quintero, 2006, p. 206). En sus peticiones de promoción dijeron ser hijos del capitán Andrés del Campo Salazar, quien sirvió a la Corona en la pacificación de indios en diversos alzamientos que hubo en la gobernación de Popayán y en los territorios del Perú, siendo de mayor importancia 
las entradas a las provincias de los Páez, Toribios y Pijaos, pueblos indios caracterizados por estar en guerra con la Corona y realizar carnicerías en donde vendían carne humana. ${ }^{1}$ Otro integrante de la familia Salazar, en este caso Francisco Javier de Salazar, mencionó en sus informaciones que poseía una real cédula que había sido concedida a su familia, para que fueran proveídos de cargos eclesiásticos por los servicios prestados por su bisabuelo, el capitán Andrés del Campo Salazar y su propio padre. Se transcribe a continuación una parte de dicho documento, en el que se demuestra que en ese sistema de reciprocidad e intercambios continuos entre el rey y sus vasallos se referían a detalle su propia historia familiar:

En favor del capitán Andrés del Campo Salazar, mi bisabuelo, por la cual encarga que el dicho Andrés del Campo como sus descendientes sean ocupados en los oficios y beneficios de este gobierno en cuyo favor [de sus abuelos] y el de su descendencia le sirvió su majestad de despachar una real cédula de recomendación para que los gobernadores en las provisiones de sus oficios acomodasen a los susodichos en remuneración de los grandes y relevantes servicios que hicieron; así el dicho Andrés del Campo como Diego del Campo, su padre en la pacificación y población de estas partes y otras como en dicha real cédula se refiere y el dicho Cristóbal de Mosquera mi abuelo sirvió así mismo mucho en las dichas conquistas y pacificaciones y en especial en las de las provincias de Páez y en esta ciudad fue muchas veces alcalde ordinario y tuvo otras muchas ocupaciones del real servicio en lo militar y el dicho maestre de campo don Fernando de Salazar mi padre sirvió así mismo a su majestad siendo teniente de gobernador en esta ciudad super intendente general muchas veces alcalde ordinario de esta ciudad y ejerciendo en ella otros oficios políticos y en la de militar el de maestro de campo tomando a su cargo el camino del puerto de la Buenaventura por comisión del gobernador don Luis Fajardo con los buenos efectos que se ha reconocido en la población de las minas de la Montaña yendo asimismo a las fronteras de las provincias del Chocó con gente y armas a su costa ayudando a la pacificación de los indios rebeldes de ella que

1 Archivo General de Indias [en adelante AGI], Audiencia de Santa Fe, «Informaciones: Pedro de Herrera Gaitán», 1651, signatura: SANTA_FE,140, N.27, f. 5. 
desde entonces pagan tributo, y asimismo soy descendiente legítimo del gobernador Francisco Mosquera de Figueroa persona tan calificada y de tan especiales servicios que en un tiempo siempre le ocuparon así los señores virreyes del Perú como la real audiencia de Quito (donde fue el primer alguacil mayor de corte que hubo en ella) en las cosas de más importancia que se ofrecía siendo muchas particularmente en las guerras continuas del Perú que se ocasionaba por muchos tiranos que hubo en aquellos principios y las continuas rebeliones de los indios recién convertidos digo conquistador y fue a quien únicamente se debió la última pacificación del reino de Perú en la nombrada batalla de Xaquixaguana ganando la victoria de gran número de indios rebelados que habían puesto en mucho cuidado todo el reino por estar por muchas partes combatido así de los tiranos que pretendían coronarse como de los dichos indios que se habían revelado y por la buena cuenta que siempre dio fue visitador general del distrito de la dicha real audiencia y quien por particular comisión dividió las jurisdicciones de las dos audiencias de Quito y Santa Fe y fue proveído por gobernador de esta provincia a más de otros muchos cargos que obtuvo ocupándose siempre en el servicio de su majestad como es público y notorio. ${ }^{2}$

Este documento expone que el peso y valoración de los méritos no recaía en una persona sino en sus familiares, por eso se recurre a enunciar tanto los servicios propios prestados como los de la familia, además de exponer un documento que vinculaba las obligaciones del rey con todo el linaje, ejemplo de nuevo del sistema de reciprocidad establecido a partir de las relaciones personales con el monarca y su representación. Hay que destacar cómo este tipo de capitulares mantiene viva la historia familiar que, en el caso de Salazar Betancur, se extiende a lo vivido tres generaciones atrás; esta memoria es un elemento fundante de las viejas familias indianas, elemento que las define como elite y que les brinda el argumento para hacer presencia en las corporaciones de poder.

2 AGI, Audiencia de Santa Fe, «Informaciones: Francisco Javier de Salazar Betancourt», 1689, sig.: SANTA_FE,143, N.6, ff. 8-8v. 
También está el caso de Agustín de Olea Salazar, nieto del capitán Diego Delgado quien, junto a Sebastián de Belalcázar, participó en la conquista del Perú y Quito, y enfrentó el levantamiento de Gonzalo Pizarro en Lima. Gracias a lo anterior logró el nombramiento de gobernador y justicia mayor de Popayán, cargo desde el que tuvo que oponerse al levantamiento general de Álvaro de Oyón, quien llegó a las puertas de la ciudad para saquearla, terminando todo con la pérdida de los sublevados, su ajusticiamiento y ejecución en Popayán. ${ }^{3}$

En estos casos se revela que los servicios pasados de los integrantes de la familia justificaban la petición presente de obtención de una recompensa, por cuanto la Corona no había satisfecho dichos servicios, con lo cual se justificaba la obtención de un nombramiento y, por ende, de una promoción en la red de catedrales indianas. La persistencia de la memoria familiar, que es acumulativa en términos generacionales, es un elemento de identificación de las elites indianas, que ayudó a definir su prestigio y honor en la sociedad local (Abadía, 2019, p. 141), y sirvió de estrategia política al asegurar una presencia informal en la estructura burocrática de la monarquía, al apelar a la reciprocidad del rey para premiar los servicios familiares acumulados en la persona de un integrante del linaje. Estos casos ligados al cabildo catedral payanés permiten hacer un análisis en dos vías: el primero, vinculado a la significación de los aportes brindados por ciertos linajes a los procesos de conquista y poblamiento payaneses; y el segundo, ligado a lo importante que resultaba que un eclesiástico perteneciera a tales linajes, puesto que así se demostraba la articulación entre servicio, familia, historia y monarquía. Los casos de los Campo Salazar y de los Olea muestran una reiteración continua de la memoria familiar, la cual, como se verá más adelante, sirvió de argumento

3 AGI, Audiencia de Quito, «Informaciones: Agustín de Olea Salazar», 1635, sig.: QUITO,51, N.12, f. 2. 
para otros integrantes y de justificante para comprender la multiplicidad de interacciones entre las familias payanesas y el cabildo catedral de Popayán.

\section{Las familias catedralicias: los Arboleda Salazar y los Sala- ZAR BETANCUR}

Son tres los tipos de vínculos generales que ayudan a entender la dimensión relacional de las conexiones que, en este caso, constituyeron los clérigos y cuadros burocráticos indianos: las amistades, las parentelas y las clientelas (Muto, 2009, pp. 151-152). Los vínculos parentales, como se refirió al principio, fueron la primera red de solidaridad y confianza (Ayllón, 2009, p. 108), y por ende, el primer circuito de gestión y apoyo de las elites indianas para acceder y acaparar cargos en las corporaciones de poder; en este sentido, como menciona Ganster, «el colocar muchos hijos en carreras eclesiásticas era parte de los esfuerzos familiares por realzar la posición y ascender en la escala social; en otros casos, este fenómeno era una respuesta a las fortunas en decadencia» (2016, p. 176). Por tanto, el pertenecer a corporaciones como los cabildos catedrales fortalecieron el honor y prestigio de estas familias de elite, además de asegurarse un estipendio económico por la congrua que recibían los prebendados. En el caso del obispado de Popayán, ¿qué linajes lograron posicionar a sus integrantes en el capítulo catedral?, ¿por qué es importante advertir estos vínculos? Son dos las redes familiares que se identificaron en el estudio prosopográfico realizado sobre el cabildo catedral de Popayán en el periodo de estudio: la de los Arboleda Salazar y la de los Salazar Betancur.

El primer integrante de la familia Arboleda en habitar Popayán fue Jacinto de Arboleda y Ortiz, nacido en Granada (España) en 1597, graduado en cánones y leyes en la Universidad de Salamanca. La primera noticia de su presencia en el Nuevo Reino de Granada 
está fechada en 1639, por un pleito sostenido con un indio cacique por el despojo de unos indios. Arboleda fue familiar del Santo Oficio en Cartagena de Indias, ${ }^{4}$ vecino de Anserma, juez de bienes de difuntos, alcalde ordinario más de catorce veces, contador, teniente de gobernador y justicia mayor en las ciudades de Arma, Toro y Anserma, pacificador de los indios de Choco y Citará, y propietario de minas de oro en Quinamayó. Su larga carrera en las corporaciones civiles y en campañas militares fue enriquecida con la decisión de seguir el camino eclesiástico, pues al enviudar se hizo clérigo y rápidamente su cursus honorum registró una importante dinámica de ascenso eclesiástico, pues pasó de ser vicario del obispado a comisario apostólico de la Santa Cruzada, para luego recibir su promoción al cabildo catedral de Popayán, donde ocupó los cargos de tesorero [1665], chantre [1667], arcediano [1668] y deán [1669]. Incluso fue reconocido por el Consejo de Indias en sus consultas en las que resultó, en 1671, promovido al deanato del cabildo catedral de Cartagena, cargo que no aceptó porque el fiat y los documentos de nombramiento no llegaron a Popayán, no obstante, de haberlo aceptado no hubiera ocupado mucho tiempo el cargo, pues murió en 1672. ${ }^{5}$ Por su parte, doña Teodora Olea y Salazar, esposa de Arboleda y Ortiz, fue nieta del capitán Diego Delgado, quien pasó a Indias en 1542 cumpliendo diversos servicios a la Corona, entre los que se cuentan el ayudar a apaciguar la rebelión de los Pizarro en el Perú y enfrentar la mencionada revuelta de Álvaro de Oyón (Quintero, 2006, p. 484). En este sentido, la familia Arboleda Salazar era por mucho un linaje de prestigio, asociado a conquistadores y oficiales reales que habían prestado múltiples servicios a la Coro-

4 Archivo Histórico Nacional [en adelante AHN], Inquisición, «Información genealógica de Jacinto de Arboleda, natural de Granada y pretendiente a familiar del Tribunal de la Inquisición de Cartagena de Indias», 1629/1630, sig.: INQUISICIÓN, 1575, Exp.450, ff. 1-5v.

5 AGI, Audiencia de Quito, «Consultas del Consejo de Indias. Propone personas para el deanato de Popayán», 18 de enero de 1673, sig.: Quito,3,111, f. 480. 
na, por lo que era natural que los hijos de dicha unión, así como sus descendientes, pidieran mercedes de la Corona y ocuparan cargos sucesivos en las corporaciones de poder local, como por ejemplo el cabildo catedral.

Dicho matrimonio tuvo seis hijos, entre quienes se cuentan: Pedro, deán en Popayán; Francisco, que ocupó los cargos de alcalde ordinario, regidor perpetuo y teniente de gobernador; Jacinto, que fue tesorero y alcalde ordinario del cabildo civil payanés; Mariana Luisa, que fue monja del convento de Nuestra Señora de la Encarnación; y Ana (Quintero, 2006, pp. 512-513). Muerto Arboleda y Ortiz, es posible identificar que otros dos integrantes de su linaje hicieron parte del cabildo catedral de Popayán: Pedro de Arboleda Salazar, hijo del mencionado, quien ocupó el cargo de maestrescuela de 1681 a 1682, y deán desde 1682 hasta 1686; ${ }^{6}$ y Carlos Fernando de Arboleda Salazar, hijo de Francisco de Arboleda Salazar y, por ende, nieto de Jacinto de Arboleda y Ortiz, quien ocupó la maestrescolía de 1720 a 1729, el arcedianato de 1729 a 1742, y el deanato entre 1742 a $1749 .{ }^{7}$ Esta reseña inicial de la primera generación de la familia Arboleda muestra un acaparamiento de cargos en las corporaciones de poder local eclesiástico, asociado a la peculiar carrera del pater familias Jacinto de Arboleda y Ortiz.

Sobre la promoción de Pedro de Arboleda Salazar, su relación de méritos y servicios fechada el 5 de abril de 1672 menciona que, por el repentino fallecimiento de su padre, adquirió «obligaciones de muchas hermanas que piden remedio y a cuyo cargo está el sustento de ellas», ${ }^{8}$ por lo que solicitaba al rey una de las prebendas que estaban vacas en la catedral de Popayán. Agregó, en 1674, en

6 AGI, Indiferente General, «Registro: Eclesiástico del Perú», 1669-1708, sig.: INDIFERENTE, 2860, L.5, ff. 220-220v.

7 AGI, Indiferente General, «Registro: iglesias del Perú», sig.: INDIFERENTE,2861, L.2, ff. 271-272v.

8 AGI, Audiencia de Quito, «Méritos de Pedro de Arboleda», Popayán, 5 de abril de 1672, sig.: QUITO,16, R.19, N.87, f. 1. 
las informaciones de oficio y parte, que «sus ilustres padres y abuelos» habían servido muy bien a la Corona tanto en la empresa de conquista «como en otras operaciones», por lo que se consideraba merecedor de una dignidad en las iglesias del Perú, ${ }^{9}$ lo que demuestra su apelación ya no a sus necesidades familiares ni a sus propios méritos, sino a los servicios ligados a la memoria familiar para obtener una promoción en aquellos obispados donde la congrua seguramente era más atractiva. ${ }^{10}$

Si bien uno de los argumentos que presentó Pedro de Arboleda para adquirir una promoción fue el relacionado a las obligaciones económicas que poseía, el inventario de bienes de su padre, realizado el 23 de julio de 1671, estableció la repartición de ciento treinta y tres esclavos entre las hijuelas fundadas para sus hijos e hijas, ${ }^{11}$ además su propio testamento, aparte de las necesidades enunciadas, menciona el no pago de la renta de su prebenda en contraste con los bienes que poseía, varios conseguidos por herencia paterna, ${ }^{12}$ con lo que se demuestra que la familia como red de solidaridad constituía dispositivos de pervivencia económica para sus integrantes, y que la pobreza aducida en la relación de méritos y en las informaciones era relativa, y más un mecanismo retórico de la época. Acceder a una promoción en una catedral indiana para diversos clérigos representó la posibilidad de acceder a posibles ascensos eclesiásticos, por lo que conseguir un cargo en una catedral con rentas pobres solo era el primer paso para poder circular por otras.

9 AGI, Audiencia de Santa Fe, «Informaciones: Pedro de Arboleda», 1674, sig.: SANTA_FE, 140, N.23, f. 1.

10 Uno de los problemas estructurales que presentó el obispado de Popayán en el periodo virreinal fue la pobreza de las rentas decimales, que resultaban insuficientes para mantener las prebendas catedralicias.

11 Archivo Central del Cauca [en adelante ACC], Notaría Primera, «Inventario de bienes», Popayán, 23 de julio de 1671, Tomo 13, 1671, ff. 34-37v.

12 ACC, Notaría Primera, «Testamento», Popayán, 28 de septiembre de 1686, Tomo 15, 1682-II, ff. 90-91v. 
Partiendo de la unidad matrimonial Arboleda - Olea Salazar se identifican los vínculos intergeneracionales que los linajes familiares, fuertemente arraigados en una sociedad como la payanesa, podían gestar al interior de las corporaciones de poder eclesiástico. Ahora bien, esta primera red de vínculos se complejiza al profundizar en el proceso de promoción catedralicia tanto de Jacinto de Arboleda y Ortiz como de su hijo Pedro de Arboleda y Salazar, al descubrir en varias cartas de recomendación a familiares que integraban ambos cabildos, así como amistades episcopales que reconocieron la importancia del linaje y el merecimiento de una promoción. En el gráfico 1 se ilustra la red de recomendaciones recibidas por padre e hijo, en la que se destaca la redactada por el obispo de Popayán, Cristóbal Bernaldo de Quirós, comprobada y validada por el cabildo civil payanés conformado, entre otros, por Francisco de Arboleda y Salazar y Jacinto de Arboleda y Salazar; también es posible advertir que tanto Pedro como su padre fueron del círculo cercano del obispo Melchor de Liñán y Cisneros, quien les ocupó en varias empresas eclesiásticas como la de ser vicarios y provisores del obispado (Evia, 1676). Cierran el círculo de influencias el obispo Vasco Jacinto de Contreras, quien nombró también como provisor del obispado a Jacinto y ordenó en el ministerio sacerdotal a Pedro. ${ }^{13}$

13 AGI, Audiencia de Santa Fe, «Informaciones: Pedro de Arboleda», 1674, sig.: SANTA_FE, 140, N.23, f. 1. 


\section{Gráfico 1}

Red de los Arboleda Salazar en el cabildo catedral de Popayán

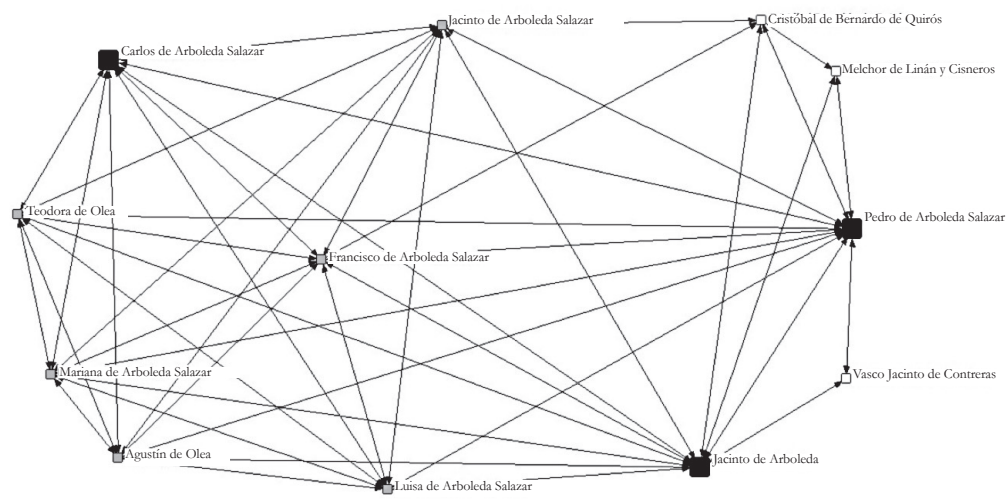

Fuente: Gráfico elaborado por la autora con documentos del Archivo General de Indias y el Archivo Central del Cauca.

Este gráfico es expresión de una red sociocentrada de relaciones que expone los vínculos familiares de los Arboleda Salazar, resaltando como egos a los tres integrantes del cabildo catedral, así como los nexos que el linaje tuvo en asuntos de promoción eclesiástica con los obispos de la ciudad de Popayán entre 1650 y 1684. Esta cercanía entre los prebendados Arboleda y los obispos de Popayán tuvo que fortalecer la corresponsabilidad, es decir, las relaciones colegiadas del cabildo eclesiástico con su entorno (Mazín, 1996, p. 36), el poder episcopal y la sociedad local. Un ejemplo de esto se encuentra en el protagonismo de los prebendados Arboleda en la toma de decisiones en Popayán, y en la continua gestión económica que permitió que la catedral se convirtiera en un relevante agente de préstamos a nivel regional (Abadía, 2019).

La segunda red familiar a trabajar es la de los Salazar Betancur, de quienes se identificaron tres generaciones presentes en el cabildo catedral payanés, con: Fernando de Salazar Betancur, tesorero 
en $1633 ;{ }^{14}$ Andrés del Campo Salazar, chantre en 1654, prebenda que ocupó por poco tiempo al ser promocionado al deanato de la catedral de Huamanga; ${ }^{15}$ su hermano Lucas del Campo Salazar, chantre entre 1656 y 1665; ${ }^{16}$ Francisco Javier de Salazar y Betancur, tesorero (1692), chantre (1694), maestrescuela (1696) y arcediano (1713) de Popayán; ${ }^{17}$ y su hermano Fernando Antonio de Salazar Betancur, quien ocupó la chantría (1699) y la maestrescolía (1696). ${ }^{18}$ En términos parentales, estos dos últimos son hijos de Fernando de Salazar Betancur y sobrinos nietos de Lucas y Andrés del Campo Salazar [ver gráfico 2].

Fernando de Salazar Betancur fue nombrado tesorero del cabildo eclesiástico el 12 de marzo de 1633, cargo que ocupó por tres años, ${ }^{19}$ hasta hacer pública dejación de él en 1635, para casarse con Elena de Mosquera y Figueroa. La razón de esta decisión se fundamentó en la baja renta de su prebenda que no le permitía solventar sus obligaciones económicas, por lo que decidió dejar el estado eclesiástico y asumir «obligaciones maritales», ${ }^{20}$ vinculándose con una de las familias descendientes de conquistadores de gran prestancia en la ciudad de Popayán: ${ }^{21}$ los Mosquera, quienes se encontraban

14 AGI, Indiferente General, «Registro: Eclesiástico General», 1585-1645, sig.: INDIFERENTE, 2859, L.3, f. 131.

15 AGI, Indiferente General, «Registro: Eclesiástico del Perú», 1646-1669, sig.: INDIFERENTE, 2860, L.4, f. 211v.

16 AGI, Indiferente General, «Registro: Eclesiástico del Perú», 1646-1669, sig.: INDIFERENTE, 2860, L.4, f. 212v.

17 AGI, Indiferente General, «Registro: Eclesiástico del Perú», 1669-1708, sig.: INDIFERENTE, 2860, L.5, ff. 224-224v.

18 AGI, Indiferente General, «Registro: Eclesiástico del Perú», 1669-1708, sig.: INDIFERENTE, 2860, L.5, ff. 220-220v.

19 AGI, Indiferente General, «Registro: Eclesiástico General», 10 de agosto de 1585 - 14 de mayo de 1645, sig.: INDIFERENTE,2859, L.3, f. 131.

20 AGI, Audiencia de Quito, «Cartas y expedientes del obispo de Popayán», Popayán, sig.: QUITO, 78, N.43, 20 de mayo de 1635, f. 1.

21 La pareja fundante del linaje Mosquera en Popayán fue la conformada por el capitán Cristóbal de Mosquera, quien fue uno de los primeros conquistadores 
emparentados vía matrimonial con la familia Salazar, cuyo tronco principal estaba asentado en el capitán Diego del Campo Salazar (Quintero, 2006, pp. 205-210).

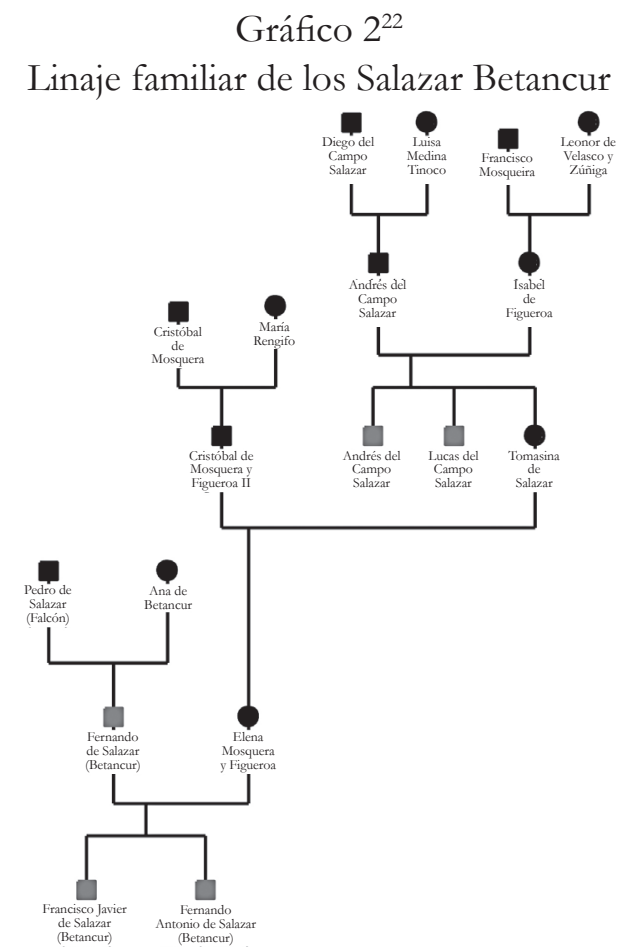

Fuente: Gráfico realizado por la autora a partir de documentos del Archivo Central del Cauca, el Archivo General de Indias y de Linajes del Cauca Grande (Quintero, 2006).

de La Florida, sirvió junto al virrey Blasco Núñez de Vela, «se halló en la conquista y población de la provincia de Beraguas, en el río San Juan, provincia de Barbacoas, y en las provincias de Páez; y figuró entre los primeros pobladores de Caloto. Fue vecino de Popayán, alguacil mayor de la gobernación en 1576 y regidor en 1585»; y doña María Rengifo, «hija legítima del capitán español Francisco Lozano Bravo» (Quintero, 2006, pp. 681-682).

22 Se hace la salvedad de que el genograma presentado no considera las amplias parentelas de las familias referidas en este, tomándose solo en cuenta, por el interés que presenta este texto, los integrantes del cabildo catedral de Popayán. 
Este gráfico expone el linaje familiar de los Salazar Betancur para resaltar en nodos grises a quienes hicieron parte del cabildo catedral de Popayán, demostrando con esto los vínculos intergeneracionales de esta familia con dicha corporación eclesiástica y los troncos de las siete familias que componen este linaje que corresponden a los primeros conquistadores del territorio indiano. Estos nexos le permitieron a la familia, pero a la vez a los prebendados Salazar, obtener recomendaciones continuas para ser tenidos en cuenta en posibles vacantes catedralicias, con lo que se confirma que la pertenencia a la corporación catedralicia brindaba apoyos continuos de los obispos, expresión, por demás, de cómo estas interconexiones entre estamentos proveían expresiones de apoyo y reciprocidad mutua.

La siguiente noticia de Fernando de Salazar Betancur es de un poder general fechado en 1655, con el que comisionó a Cristóbal Bernaldo de Quirós, chantre de la catedral de Quito, después obispo de Popayán, para que, junto a otras autoridades, le representaran en cualquier pleito en la capital quiteña; en dicho documento se mencionaba que Salazar se encontraba avecindado en Buga, donde era capitán de infantería. Este vínculo con Bernaldo de Quirós tuvo que motivar una relación de cercanía y amistad, pues este último en 1681, ya siendo prelado en Popayán, dirigió al Consejo de Indias y al rey una carta recomendando a los diez hijos de Salazar Betancur, muerto en 1669 , por haber prestado significativos servicios a la Corona, por lo que a consideración del obispo el rey podría favorecerlos con alguna merced a la familia completa, que estaba compuesta «tanto [de] número de pobres y nobles, religiosos, sacerdotes y seculares todos descendientes de antiguos conquistadores». ${ }^{23}$ En este caso, el vínculo de amistad y cercanía de Bernaldo de Quirós con los Salazar permite referir cómo los nexos cumplían un rol fundamental para generar procesos de colaboración, apoyo y recomendación

23 AGI, Audiencia de Quito, «Cartas y expedientes del obispo de Popayán», Popayán, 20 de septiembre de 1681, sig.: QUITO,79, N.8, f. 1. 
que, en últimas, son muestra del sistema de reciprocidad estamental, cotidiano y administrativo de la época.

La carta del obispo Bernaldo de Quirós brinda también algunos datos y características de los hijos Salazar Betancur, los cuales se mencionan a continuación: Pedro de Salazar Betancur, presbítero; el maestro don Francisco Javier de Salazar Betancur, quien junto a su hermano Fernando, hicieron parte del cabildo catedral de Popayán, ${ }^{24}$ este último fue destacado por el obispo porque se había ordenado sacerdote en la universidad en Santa Fe de «licenciado y maestro en la sagrada teología con lucida letra y estimación», ${ }^{25}$ fray Cristóbal, religioso agustino; Luis Antonio, regidor y procurador de la ciudad de Buga; y Jacinto, corregidor de los indios de Popayán ${ }^{26}$ y, según Quintero (2006, p. 687), oficial real en Quito; Juana de San Javier y Elena de la Cruz, monjas del convento de la Concepción de Quito; María de Santa Bárbara, Josefa de Santa Elena y Tomasa de San Agustín, monjas del convento de Nuestra Señora de la Encarnación de Popayán; y Gregoria, de quien no se tienen mayores datos. Esta información, a pesar de ser descriptiva, demuestra la vinculación corporativa de un linaje familiar en diversas instituciones payanesas, santafereñas y quiteñas, que es muestra de la complejidad y extensión de los nexos políticos de dichas familias, pero, a la vez, de la fortaleza de estas elites que, a pesar de ser locales, tenían representación continua en los espacios significativos del poder.

Hay que advertir que la presencia del obispo en los ejes relacionales de las dos redes familiares debe ser entendida como una

24 Francisco Javier de Salazar Betancur estuvo por siete años ocupando diversas prebendas del cabildo, puntualmente la tesorería, la chantría y el arcedianato, mientras su hermano Fernando estuvo trece años entre la tesorería, la maestrescolía y la chantría.

25 AGI, «Cartas y expedientes del obispo de Popayán», 20 de septiembre de 1681, f. 1.

26 AGI, «Cartas y expedientes», 20 de septiembre de 1681, f. 1. 
expresión de las relaciones vinculantes del poder episcopal con las elites de poder payanés, situación por demás importante teniendo en cuenta que los obispos, al ser agentes de la monarquía, podían ser vistos como foráneos por las corporaciones y elites locales. Esto es importante en tanto, como menciona Artola (2017), por lo general los prelados al llegar a sus nuevas sedes enfrentaban múltiples conflictos con las familias locales, al ver desafiadas sus prácticas por el deseo continuo de los obispos de reformar las costumbres de los habitantes de sus obispados. Bernaldo de Quirós es el prelado con uno de los periodos de administración obispal más prolongados en Popayán, al ser nombrado para este cargo en 1672 y morir ejerciéndolo en 1684 (Abadía, 2018); su presencia en el ejercicio de la administración episcopal pudo beneficiar un acercamiento a las familias payanesas, y con esto obtener el conocimiento que le permitió establecer permanentes vínculos de amistad y patronazgo.

Más allá de estos procesos particulares, la promoción eclesiástica encierra una relación vinculante entre la Corona y las elites indianas, relación que Jean Pierre Dedieu identifica como existente desde la Edad Media entre los reyes, sus cortes, asambleas y patriciados (2000, pp. 20-21). Esta dinámica relacional, que también tiene presencia en el periodo virreinal indiano, no es unilateral, no beneficiaba a uno solo de estos agentes, pues a cambio de los servicios que se prestaban a la Corona, esta «premiaba» tal fidelidad y lealtad con cargos y nombramientos a las familias descendientes de conquistadores, colonizadores y oficiales reales que fueron lentamente convirtiéndose en elite y grupo de poder. Durante el reinado de la casa de los Austrias este «intercambio de servicios», que bien podían ser individuales o colectivos, determinó en buena parte los nombramientos corporativos y gestó una premisa importante para vincular circulaciones, méritos, servicios, conflictos y redes de poder: «gobernar significa administrar también relaciones privadas» (Dedieu, 2000, p. 23). 


\section{VínCulos de patronazgo entre EClesiásticos: El CASO DE MI- guel de Ressa Montoya}

Entre los vínculos estudiados a partir de los cursus honorum de los capitulares del capítulo catedral payanés se identificaron relaciones de patronazgo, definidas como el amparo y apoyo que ejercían ciertas familias y corporaciones sobre sus candidatos (Aguirre, 2003, p. 19), con el fin de beneficiar las aspiraciones a un nombramiento o cargo, en este caso, en las instituciones eclesiásticas. No es gratuito que integrantes de cabildos catedrales, cabildos civiles y audiencias enviaran a la corte sendas recomendaciones de candidatos para que fueran nombrados en cargos de alto nivel en la ciudad en la que estaban asentados, asegurando con esto el control del poder local. ${ }^{27}$ De hecho, el patronazgo puede entenderse a partir de diversos tipos de vínculos: 1) de los prelados, 2) de familiares y criados de obispos, 3) de prelados a capitulares, 4) de cabildos catedralicios, y 5) de familia consanguínea (Aguirre, 2003, pp. 163-213).

Estudiar estos vínculos patronales resulta fundamental para comprender las características de las carreras eclesiásticas en el escenario indiano, ya que, si bien no tienen una condición fortuita, beneficiaron por mucho la realización de estudios superiores, la constitución de una opinión relevante en escenarios como el Consejo de Indias, y las trayectorias de los candidatos a diversas mercedes y cargos que componían la institucionalidad de la Iglesia católica en el mundo hispánico. Tener un patrono - fuera este un obispo, un familiar o un prebendado- aseguraba desde diversos mecanismos contextuales tener un «apoyo, padrinazgo o recomendación» (Jaramillo, 2016, p. 253), que permitiera el ascenso en los procesos de promoción eclesiástica.

27 Hay que resaltar que no fue posible identificar relaciones de compadrazgo, que sí se evidencian en el caso de México, dado que no se encontraron fuentes históricas que pudieran identificar estas. 
En la revisión prosopográfica realizada para advertir este tipo de relaciones patronales resalta el caso de Miguel Ramírez de Ressa y Montoya, quien ocupó diversas prebendas en el capítulo eclesiástico de Popayán entre 1685 y 1717, periodo en el que fue maestrescuela (1685-1689), chantre (1688-1691) y deán (1691-1717). ${ }^{28} \mathrm{Su}$ importancia en la historia del cabildo catedral payanés fue determinante, porque entre 1689 y 1695 recayeron en él «los deberes de la catedral y de su cabildo» (Abadía, 2019, p. 120), al ser el único capitular nombrado presente en Popayán. Paradójicamente no encontré relaciones de méritos y servicios, ni informaciones de oficio y parte que hicieran mención de su carrera, solo una carta fechada en 1669, escrita por el entonces obispo de Popayán, Melchor de Liñán y Cisneros al Consejo de Indias, en la que indicaba que Ressa y Montoya era natural de Popayán, licenciado, cura doctrinero del pueblo de Guambia, visitador del obispado, «y que sus antepasados han hecho también muy buenos servicios a los señores reyes antecesores». ${ }^{29}$ La revisión de los protocolos notariales y una petición elevada por otro prebendado permitieron establecer en su carrera eclesiástica relaciones de patronazgo, ejemplo de cómo este tipo de relaciones clientelares beneficiaban el ascenso social de los clérigos.

Según revela el testamento de Francisco Ramírez Florián, maestrescuela (1620-1638), arcediano (1638-1640) y deán (16401651) ${ }^{30}$ del cabildo catedral de Popayán, este fue tío de Ressa y Montoya, a quien declaró en su testamento como uno de sus herederos universales, ${ }^{31}$ por lo que se hizo merecedor de diversas tierras

28 AGI, Indiferente General, «Registro: Eclesiástico del Perú», 1669-1718, sig.: INDIFERENTE, 2860, L.5, ff. 220v, 222-222v.

29 AGI, Audiencia de Quito, «Cartas y expedientes del obispo de Popayán», Popayán, 23 de enero de 1669, sig.: ES.41091.AGI/23.12.5.22.1//QUITO,8, N.58, f. 6.

30 AGI, Indiferente General, «Registro: Eclesiástico general», 1585-1645, sig.: INDIFERENTE, 2859, L.3, ff. 130v, 132-132v.

31 ACC, Notaría Primera, «Poder para testan», Popayán, 20 de febrero de 1651, Tomo 11, 1651, f. 21. 
que fueron de su abuela, Isabel Núñez, ${ }^{32}$ y de varias propiedades ubicadas en la traza urbana de la ciudad de Popayán, ${ }^{33}$ patrimonio en general que sirvió de apoyo económico para su carrera. Esta suficiencia económica le permitió traspasar a Luis de Ressa Montoya, su hijo natural y quien deseaba seguir la carrera eclesiástica, una capellanía impuesta por Alonso de Fuenlabrada en 1653, por un valor de 1,990 pesos de oro, que estaba a su cargo y con la que pudo ordenarse como clérigo. ${ }^{34}$ Wobeser, citando a Ots Capdequí, define la capellanía como «una fundación en la cual se imponía la celebración de cierto número de misas anuales en determinada capilla, iglesia o altar, afectando para su sostenimiento las rentas de los bienes que se especificaban» (2010, p. 39), así que el capellán encargado de dichas misas quedaba encargado de realizarlas, por lo que recibía una renta, que para el caso de los clérigos, fue un estipendio fundamental para financiar diversas necesidades concernientes con el ministerio sacerdotal. Dicho traspaso debe verse como una expresión patronal-parental, por cuanto Miguel de Ressa beneficiaba con esto la carrera eclesiástica y, en un futuro, la posición social

32 ACC, Notaría Primera, «Cesión y traspaso», Popayán, 5 de mayo de 1667, Tomo 13, 1667-II, f. 33.

33 Las transacciones de esos inmuebles rentan lo siguiente: en 1667 vendió un solar cuadrado a Pedro de Espinosa en 150 patacones y otro solar a Catalina García en 100 patacones; además hizo donación en 1695 de medio solar de tierra a Bárbara de Sevilla por haberle servido y cuidado de su persona y de su casa; y en 1705 , de un pedazo de tierra de 26 varas de largo y 23 de ancho y de medio solar en el barrio de la ermita de Jesús Nacianceno, a su primo, Alonso Baca de Ortega, "por el mucho amor y buena voluntad conque le ha asistido en muchas ocasiones».

34 El protocolo notarial en mención, aparte de brindar los datos de la transacción, no brinda mayores datos personales de este hijo natural, aparte de la afirmación de que Miguel de Ressa Montoya «lo había criado en casa»; sin embargo, hay que anotar como hipótesis que probablemente fue un hijo concebido antes de ingresar a la carrera sacerdotal, lo cual pudo posibilitar que lo criara y mantuviera. Ver: ACC, Notaría Primera, «Traspaso», Popayán, 18 de febrero de 1682, Tomo 15,1682 , ff. $34 \mathrm{v}-35$. 
de su hijo y clérigo. Se denota, entonces, cómo estas heredades y fundaciones piadosas eran formas de apoyo patronal, en este caso económico, a las carreras eclesiásticas futuras de los integrantes de un linaje familiar. Este tipo de estrategias permitían que los clérigos tuvieran seguridad para realizar sus estudios y sobrevivencia hasta que obtuvieran un beneficio eclesiástico.

Ressa Montoya también colaboró en la carrera eclesiástica de Miguel de Castillo, clérigo que fue maestrescuela (1717), chantre (1717-1729) y deán (1729-1741) del cabildo catedral payanés. Castillo fue un niño expósito, sin padres conocidos y acogido por la iglesia católica, en este caso por la catedral de Popayán, en cabeza del deán Ressa Montoya. Sobre la infancia de Castillo los documentos indican que fue abandonado en la puerta de la casa de Bernarda del Castillo, quien lo encontró enfermo y a punto de morir, encargándose de su bautizo y cuidado hasta que fue recogido por el citado deán quien lo alimentó y crió, además de hacerlo partícipe de los quehaceres catedralicios y enviarlo a «estudiar [...] a la ciudad de Quito y lo mantuvo en ella hasta que se graduó de doctor y volvió a esta ciudad [Popayán]». ${ }^{35}$ El vínculo entre Ressa Montoya y Castillo fue trascendente en la sociedad payanesa, pues se reconoció al segundo como «pupilo del señor deán [...] quien lo tenía de monigote sirviendo en la santa iglesia catedral de esta ciudad, acudiéndole con todo lo necesario». ${ }^{36} \mathrm{El}$ apoyo de Ressa Montoya no debe ser solo interpretado desde la obligación de la iglesia para con los hijos espurios y abandonados, sino como expresión de una relación patronal en la que el deán jugó un papel fundamental para que su pupilo siguiera la senda de la carrera eclesiástica, a pesar de que su cualidad ex defectu nattalium podía obstaculizar cualquier pretensión a

35 AGI, Audiencia de Quito, «Sobre las reclamaciones de don Miguel del Castillo», 1700/1728, sig.: QUITO, 202, f. 58.

36 AGI, «Sobre las reclamaciones», 1700/1728, f. 61v. 
un nombramiento, ascenso o beneficio eclesiástico, ${ }^{37}$ situación que en el caso de Castillo no se presentó, dados sus nombramientos y ascenso eclesiástico en la catedral de Popayán.

\section{Conclusiones}

Los cursus honorum de los eclesiásticos no solo deben comprender la identificación y análisis de sus méritos y servicios, sino también la de su linaje familiar, al igual que las relaciones gestadas y expresadas a lo largo de la carrera eclesiástica. Así no solo se estudia la trayectoria y carrera del individuo, sino que a la vez se resignifica su pertenencia a un colectivo a partir de una perspectiva relacional, en la que se tienen en cuenta los vínculos como elementos históricos con repercusión en los procesos de promoción eclesiástica, por lo menos para el mundo indiano.

Si bien era decisión final del rey la elección de candidatos a cargos eclesiásticos en obispados, arzobispados y cabildos eclesiásticos, los vínculos y relaciones de estos son fundamentales para conocer los tipos de clientelas y patronazgos que tuvieron y que fueron determinantes para el fortalecimiento de las carreras eclesiásticas. Con esto, fue posible advertir en este texto que la composición del cabildo catedral de Popayán contó con dos redes familiares, cuya característica principal fue la concurrencia intergeneracional de integrantes de las familias Arboleda Salazar y Salazar Betancur en las prebendas del cabildo catedral de Popayán.

Para el cabildo eclesiástico payanés se presenta, sobre todo, el patronazgo ejercido por los obispos con su clerecía, por el cabildo

37 Tales documentos fueron fundamentales para que del Castillo pudiera defender sus nombramientos frente a uno de sus opositores: el obispo Juan Gómez de Frías, quien no le consideraba apto por la condición tan poco honrosa de su nacimiento. 
eclesiástico con sus capitulares, y el familiar. Si bien resultaría muy extenso hacer las menciones concretas de este tipo de vínculos, es posible encontrar el padrinazgo de familias y apoyo clientelar de corporaciones a las carreras de capitulares, e incluso de obispos del episcopado payanés. Con esto quiero confirmar la importancia del estudio de las relaciones para identificar las injerencias de estas en el panorama de la política eclesiástica indiana y en el proceso de promoción establecido desde el Regio Patronato. Así, el análisis relacional permite proponer la posibilidad de vincular episcopados, catedrales y elites en un esfuerzo por demostrar, a pesar de la distancia, las posibilidades de vinculación que existieron en el siglo XVII entre las elites indianas y el rey.

\section{ARCHIVOS}

Archivo Central del Cauca (Popayán, Colombia)

Notaría Primera.

Archivo General de Indias (Sevilla, España)

Audiencia de Quito.

Audiencia de Santa Fe.

Indiferente General.

Archivo Histórico Nacional (Madrid, España)

Inquisición.

\section{REFERENCIAS}

Abadía Quintero, Carolina (2018). «Cristóbal Bernaldo de Quirós, “el obispo indigno". Promoción religiosa, vida privada, méritos y servicios de un prelado en Indias, 1618-1684». En: A. Santos Delgado, R. Silva y A. J. Echeverry Pérez (eds.). Historia, política y sociedad. Investigaciones sobre ámbitos de la realidad moderna y contemporánea del Valle del Cauca. Cali: Universidad del Valle, pp. 243-268. 
Abadía Quintero, Carolina (2019). La notoria virtud de un mérito. Redes complejas, poder eclesiástico y negociación politica en las Indias Meridionales. El caso del obispado de Popayán, 1546-1714. Tesis de doctorado. Michoacán: El Colegio de Michoacán A.C.

Abadía Quintero, Carolina (2020). Informe final programa Fomento a la investigación 2020: Crédito eclesiástico y sistema de empréstitos de la catedral de Popayán, 1592-1790. Instituto Colombiano de Antropología e Historia, https://www.icanh.gov.co/recursos_user/ editores/1539/Informes_\%C3\%81rea_Historia_2020/Informe_Final_-_Carolina_Abadia_Quintero.pdf. Consultado el 2 de mayo de 2021.

Aguirre Salvador, Rodolfo (2003). El mérito y la estrategia. Clérigos, juristas y médicos en Nueva España. Primera edición. México: Universidad Nacional Autónoma de México; Plaza y Valdés Editores.

Aguirre Salvador, Rodolfo (ed.) (2004). Carrera, linaje y patronazgo. Clérigos y juristas en Nueva España, Chile y Perú (siglos XVI - XVIII). México: Universidad Nacional Autónoma de México; Plaza y Valdés Editores.

Aguirre Salvador, Rodolfo (2008). «De las aulas al Cabildo Eclesiástico. Familiares, amigos y patrones en el Arzobispado de México, 16801730». Tzintzun: Revista de Estudios Históricos, núm. 47, pp. 75-114.

Artola Renedo, Andoni (2011). «El patrocinio intraclerical en el Antiguo Régimen: Curias y familias episcopales de los arzobispos de Toledo (1755-1823)». Redes. Revista hispana para el análisis de redes sociales, núm. 21, pp. 273-300.

Artola Renedo, Andoni (2017). «El obispo, la monarquía, los poderes locales. La política de destinos episcopales en la segunda mitad del siglo XVIII». En: Michel Bertrand, Francisco Andújar y Thomas Glesener (eds.). Gobernar y reformar la monarquía. Los agentes politicos y administrativos en España y América. Siglos XVI- XIX. Valencia: Albatros Ediciones, pp. 187-200. 
Ayllón Gutiérrez, C. (2009). «Los Soriano: Otro linaje eclesiástico en el cabildo de Cartagena». Murgetana, núm. 120, pp. 95-110.

Castillo Flores, J. G. (2013). La catedral de México y su cabildo eclesiástico, 1530 1612. Tesis de doctorado. Michoacán: El Colegio de Michoacán A.C.

Dedieu, Jean Pierre (2000). «Procesos y redes. La historia de las instituciones administrativas de la época moderna, hoy». En: Jean Pierre Dedieu, Juan Luis Castellano y María Victoria López-Cordón (eds.). La pluma, la mitra y la espada. Estudios de historia institucional en la Edad Moderna. Madrid: Marcial Pons, pp. 13-30.

Dedieu, Jean Pierre (2005). «Amistad, familia, patria... y rey. Las bases de la vida política en la Monarquía española de los siglos XVII y XVIII». Melanges de la Casa de Velárquez, vol. 35, núm. 1, pp. 27-50.

EnRíQueZ, Lucrecia (2004). «Carrera eclesiástica, Real Patronato y redes de poder en las consultas de la Cámara de Indias del clero secular chileno en el siglo XVIII». En: Rodolfo Aguirre Salvador (ed.). Carrera, linaje y patronazgo. Clérigos y juristas en Nueva España, Chile y Perú (siglos XVI - XVIII). México: Universidad Nacional Autónoma de México; Plaza y Valdés, pp. 121-150.

ENRíQueZ, Lucrecia (2005). De colonial a nacional: La carrera eclesiástica del clero secular chileno entre 1650 y 1810. México: Instituto Panamericano de Geografía e Historia.

EviA, X. de (1676). Ramillete de varias flores poéticas, recogidas y cultivadas en los primeros Abriles de sus años. Madrid: Imprenta de Nicolás de Xamares, Mercader de Libros. Disponible en: <http://bdh-rd. bne.es $/$ viewer.vm?id $=0000078071$ \&page $=1>$. Consultado el 15 de diciembre de 2020.

Ganster, P. (2016). «Miembros de los cabildos eclesiásticos y sus familias en Lima y la Ciudad de México en el siglo XVIII». En: Leticia Pérez Puente y Gabino Castillo Flores (eds.). Poder y privilegio: Cabildos 
eclesiásticos en Nueva España, siglos XVI a XIX. México: Universidad Nacional Autónoma de México, pp. 175-188.

Imízcoz, José María (ed.) (2001). Redes familiares y patrona goo. Aproximación al entramado social del País Vasco y Navarra en el Antiguo Régimen (siglos $X V$-XIX). Bilbao: Universidad del País Vasco.

Imízcoz, José María (2017). «El paradigma relacional. Actores, redes, procesos para una historia global». En: Michel Bertrand, Francisco Andújar y Thomas Glesener (eds.). Gobernar y reformar la monarquía. Los agentes políticos y administrativos en España y América. Siglos XVI-XIX. Valencia: Albatros Ediciones, pp. 65-80.

Irigoyen López, A. (2018). «Sobre los contenidos y alcance del concepto de familia en perspectiva histórica». En: Estructuras, coyunturas y representaciones. Perspectivas desde los estudios de las formas familiares (pp. 21-27). Ediciones de la Universidad de Murcia.

Jaramillo, Juvenal (2016). «De una familia episcopal a un cabildo catedral. Aspectos sobre un mecanismo de acceso a los cabildos eclesiásticos en la Nueva España». En: Leticia Pérez Puente y G. Castillo Flores (eds.). Poder y privilegio: Cabildos eclesiásticos en Nueva España, siglos XVI a XIX. Universidad Nacional Autónoma de México, Instituto de Investigaciones sobre la Universidad y la Educación, pp. 253-274.

Lindorfer, Bianca María (2009). «Las redes familiares de la aristocracia austriaca y los procesos de transferencia cultural: Entre Madrid y Viena, 1550-1700». En: Bartolomé Yun Casalilla (ed.). Las redes del imperio. Élites sociales en la articulación de la monarquía hispánica, 1492-1714. Madrid: Marcial Pons Historia; Universidad Pablo de Olavide, pp. 261-288.

Macleod, M. J. (1998). «Self-Promotion: The Relaciones de Méritos y Servicios and Their Historical and Political Interpretation». CLAHR. Colonial Latin American Historical Review, vol. 7, núm. 1, pp. 25-42. 
Martínez Millán, J. (1996). «Las investigaciones sobre patronazgo y clientelismo en la administración de la monarquía hispana durante la edad moderna». Studia historica. Historia moderna, 15, pp. 83-106.

Marzahl, P. (2013). Una ciudad en el Imperio. El gobierno, la política y la sociedad de Popayán en el siglo XVII. Universidad del Cauca.

Mazín, Óscar (1991). «Capítulo I. La catedral de Valladolid y su cabildo eclesiástico». En: Nelly Sigaut (ed.). La catedral de Morelia. Michoacán: El Colegio de Michoacán A.C.; Gobierno del Estado de Michoacán, pp. 17-63.

Mazín, Óscar (1996). El cabildo catedral de Valladolid de Michoacán. Zamora: El Colegio de Michoacán, A.C.

Mazín, Óscar (2007). Gestores de la real justicia. Procuradores y agentes de las catedrales hispanas nuevas en la corte de Madrid. I. El ciclo de México, 1568-1640. México: El Colegio de México.

Muto, G. (2009). «La nobleza napolitana en el contexto de la Monarquía Hispánica: Algunos planteamientos». En: Bartolomé Yun Casalilla (ed.). Las redes del imperio. Élites sociales en la articulación de la monarquia hispánica, 1492-1714. Madrid: Marcial Pons Historia - Universidad Pablo de Olavide, pp. 135-172.

Olival, Fernanda y Goncalo Monteiro (2003). «Mobilidade social nas carreiras eclesiásticas em Portugal (1500 - 1820)». Análise Social 37, núm. 165, pp. 1213-1239.

Ortiz, J. B. y Manuel Antonio Bueno y Qujano (1945). Historia de la diócesis de Popayán, dos estudios. Bogotá: Editorial ABC.

Pérez Puente, Leticia (2005). Tiempos de crisis, tiempos de consolidación. La catedral metropolitana de la ciudad de México, 1653-1680. México: Universidad Nacional Autónoma de México; El Colegio de Michoacán, A.C.; Plaza y Valdés Editores. 
Quintero Guzmán, Miguel W. (2006). Linajes del Cauca Grande. Fuentes para la Historia. Tomo 1. Bogotá: Universidad de los Andes; Facultad de Ciencias Sociales.

ReVel, Jacques (1995). «Micro-análisis y construcción de lo social». Anuario IEHS, núm. 10, pp. 125-143.

Wobeser, G. von (2010). El crédito eclesiástico en la Nueva España. Siglo XVIII. México: Universidad Nacional Autónoma de México; Fondo de Cultura Económica.

Fecha de recepción: 2 de febrero de 2021.

Fecha de evaluación: 21 de marzo de 2021.

Fecha de aceptación: 7 de junio de 2021.

Fecha de publicación: 1 de noviembre de 2021.

(9) (1) (8) 